\title{
High mean platelet volume after myocardial infarction: is it due to consumption of small platelets?
}

\author{
ROGER SEWELL，R M IBBOTSON，ROSALIND PHILLIPS， PETER CARSON
}

\begin{abstract}
Seventy nine men surviving after sustaining a myocardial infarction in 1982, and who had at that time had raised mean platelet volumes compared with controls, were followed up after 18 months. The shape of each man's platelet distribution curve was calculated from the mean platelet volume, platelet count, and platelet distribution width. The calculated curves were in close agreement with the curves plotted by the Coulter counter from the raw data. These curves did not differ significantly from those of a current control group, but the curves plotted from the variables measured at the time of myocardial infarction in 1982 showed a deficit of platelets in the volume range 5-12 $\mathrm{fl}$ amounting at maximum to $30 \%(p<0.0001)$; there were no significant differences above $12 \mathrm{fl}$. The deficit of small platelets became more appreciable during initial admission, was less at one month's follow up, and had disappeared at one year.
\end{abstract}

The deficit of small platelets is probably an effect rather than a cause of infarction.

\section{Introduction}

In 1983 our group ${ }^{1}$ and Martin et $a^{2}$ reported that patients who had recently suffered an acute myocardial infarction had a raised mean platelet volume compared with control patients. We speculated that this might have been due to an excess of large platelets, which could have been a contributory cause of the myocardial infarction as large platelets are thought to be more active than small ones in haemostasis. ${ }^{3}$ We therefore sought to determine whether there was in fact an increase in large platelets or a reduction in small ones and whether there was any evidence that the increase in mean platelet volume preceded the myocardial infarction.

\section{Patients and methods}

We studied patients, originally reported on by Cameron et al, who had sustained a myocardial infarction in 1982. At that time our group did not record the platelet volume distributions directly from the Coulter counter, but we believe that these data may be derived from measured variables as follows. In a single patient platelet volumes are known to be log normally distributed. ${ }^{4}$ When measuring platelets the Coulter counter starts by plotting a histogram of particle count at each platelet volume from 2 to $20 \mathrm{fl}$. It then fits a curve of the form

$$
y=\frac{\mathrm{pe}^{-\frac{1}{2}\left(\frac{\ln (\mathrm{x})-\mathrm{m}}{\mathrm{s}}\right)^{2}}}{\mathrm{xs}}
$$

North Staffordshire Hospital Centre, Stoke on Trent ROGER SEWELL, MA, MRCP, registrar, department of cardiology R M IBBOTSON, MRCP, MRCPATH, consultant haematologist

ROSALIND PHILLIPS, MB, BS, clinical assistant, department of cardiology

PETER CARSON, FRCP, FACC, consultant cardiologist and senior research fellow

Correspondence and requests for reprints to: Dr P Carson, Department of Cardiology, City General Hospital, Stoke on Trent. to this histogram (in which $\mathrm{p}, \mathrm{m}$, and $\mathrm{s}$ are variables controlling the distribution shape, $x$ is platelet volume, $e$ is the base of natural logarithms, and $\ln (\mathbf{x})$ represents the natural logarithm of $\mathbf{x})$. From this curve it calculates the total platelet count and the mean platelet volume. The platelet distribution width is defined as being a constant times the ratio of the 90th and 10th centiles of the histogram. If this ratio is assumed to be linearly related to the same ratio measured on the fitted curve $\mathrm{p}, \mathrm{m}$, and $\mathrm{s}$ can be extracted from total platelet count, mean platelet volume, and platelet distribution width. Hence the fitted curve can be found without having plotted it at the time the platelets were measured.

We tested this assumption on the surviving patients studied by Cameron et al, ${ }^{1}$ plotting both the raw data from the Coulter $S$ and also the approximation to the fitted curve. There were few discrepancies; most fitted as well as in the upper part of figure 1;
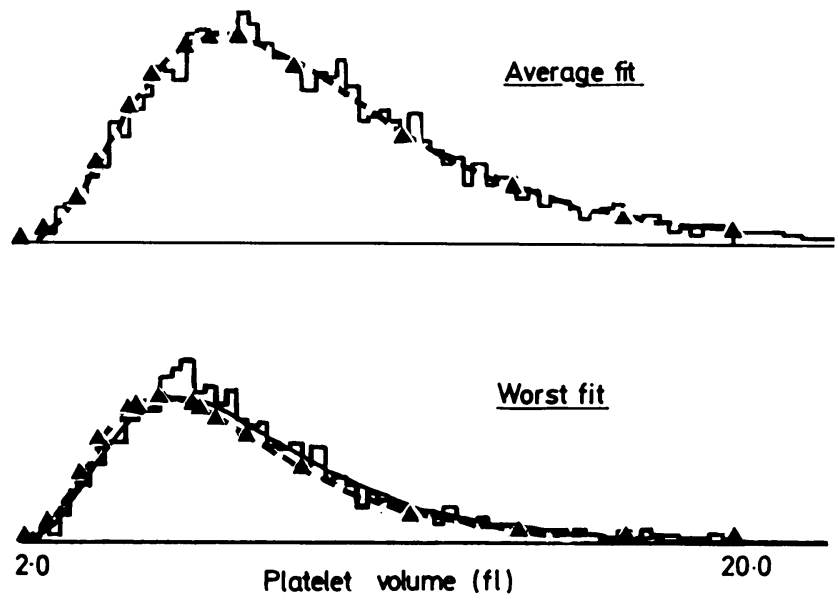

FIG 1-Histograms of platelet volume distribution together with Coulter fitted curves $(\longrightarrow)$ and back plotted curves $(\boldsymbol{\Lambda}--\boldsymbol{\Lambda})$.

figure 1 also shows the worst fitting curve. We therefore applied this technique both to the original data collected by Cameron et al, reported in 1983, ${ }^{1}$ and to current platelet variables measured in the follow up clinic. We also compared the curves for one month after myocardial infarction of those patients who did not subsequently reinfarct with the curves of those who did to see whether there was evidence of high mean platelet volume being a risk factor for myocardial infarction.

Collection and processing of platelet samples was as for the study of Cameron et al, using edetic acid collection tubes and a Coulter $S$ Plus counter. ${ }^{1}$

We defined the absolute platelet frequency at a given volume for a given patient as the total platelet count multiplied by the amplitude of the Coulter derived platelet volume frequency distribution at that volume. Thus if the absolute platelet frequency at $10 \mathrm{fl}$ for a patient was $23 \times 10^{3}$ platelets $/ \mu \mathrm{l} / \mathrm{fl}$ that patient had roughly $23 \times 10^{3}$ circulating platelets $/ \mu$ l that were between 9.5 and $10.5 \mathrm{fl}$ in volume.

The 100 patients admitted to the study of Cameron et al were considered for admission to this study. We excluded one whose hospital records could not be located; thus 99 patients entered the initial stage. Of these, 13 had died before one month and five had defaulted from follow up at one month; these were excluded from all the data to be reported below. Seven had died between one month and 18 months, five of further myocardial infarction and two of other causes. Four patients who were known to be alive were excluded from follow up at 18 months because they did not wish to attend. Thus 79 patients were followed up from one to 18 monthi or died within that period. The table shows the characteristics of the patients studied. 
BRITISH MEDICAL JOURNAL VOLUME $289 \quad 8$ DECEMBER 1984

Seventy two of the 79 patients survived until follow up at 18 months, and all but five were then assessed clinically with 12 lead electrocardiography by one of us (RFS) without knowledge of the patient's platelet variables. We determined whether a further myocardial infarction had occurred between one and 18 months. The patients' platelet variables were then measured again.

The following criteria were considered as evidence of a further myocardial infarction: $Q$ waves on the electrocardiogram that were new since the electrocardiogram recorded at one month; new $T$ inversion in more than two leads; hospital admission because of chest pain associated with rise in serum glutamate-oxaloacetate transaminase and lactate dehydrogenase activities not associated with rises in alkaline phosphatase or $\gamma$-glutamyltransferase activities; death of patient with changes associated with acute myocardial infarction at postmortem examination; or death of patient without postmortem examination but with myocardial infarction recorded on death certificate.

As controls for the data collected in 1982 at the patient's admission and at follow up after one month we selected the records of the first two men of matching age ( \pm 10 years) on whom data were available, in the pathology department records, for the month during which a patient's sample was taken. These records were filed in alphabetical order. We excluded any patients with a history of myocardial infarction or thromboembolic disease recorded on the laboratory request card. The original control groups of the study by Cameron et al could not be used because their platelet distribution widths had not been recorded. For the data collected at follow up after 18 months we selected the records of the first two men of matching age for whom results were currently passing through the haematology laboratory. Again we excluded patients with a history of myocardial infarction or thromboembolic disease.

The two controls for each patient were put separately into two control groups, and each group was used separately for each comparison; results using each control group were similar, and the results for the first control group alone are presented below.

Student's $t$ test was used for comparison of the mean absolute platelet frequencies at any given platelet volume in patients and controls.

\section{Results}

During initial admission the absolute platelet frequencies at all platelet volumes between 2.5 and $12 \mathrm{fl}$ were significantly less in patients $(26.3(\mathrm{SD} 0.8) \times 1000$ platelets $/ \mu \mathrm{l} / \mathrm{fl}$ at $5 \mathrm{fl})$ than in controls $(37.8(1.4))(\mathrm{p}<0.0001)$. This difference was significant on day 1 and had become significantly greater by day 3 (fig 2 ). Linear extrapolation backwards would suggest that patients had normal values on the day before infarction, although there is no certainty that the time course of this fall is linear. At one month this difference had decreased and at 18 months it was not significant (patients $31 \cdot 6(1 \cdot 0)$ at $5 \mathrm{fl}$; controls $33.8(1 \cdot 0) ; \mathrm{p}=0 \cdot 2$ ) (fig 3).

These results remained essentially unchanged even when those seven patients who subsequently died were excluded from the study from the beginning; the return towards normality at one year was therefore not just due to those patients with low absolute platelet frequencies at $5 \mathrm{fl}$ having died before the 18 month follow up. (Those patients who died before one month were in any case excluded from all the data in this paper, and the progression seen in figure 2 is therefore similarly free from difficulties in interpretation due to a changing population under study.)

\begin{tabular}{lccccc}
\hline & & \multicolumn{4}{c}{ Patients : } \\
\cline { 3 - 6 } & $\begin{array}{c}\text { All } \\
\text { patients } \\
(\mathrm{n}=99)\end{array}$ & $\begin{array}{c}\text { Seen at Followed up } \\
\text { one } \\
\text { month } \\
(\mathrm{n}=81)\end{array}$ & $\begin{array}{c}\text { or dead at } \\
\text { months } \\
(\mathrm{n}=79)\end{array}$ & $\begin{array}{c}\text { Rein- } \\
\text { farcting } \\
(\mathrm{n}=15)\end{array}$ & $\begin{array}{c}\text { Not } \\
\text { rein- } \\
\text { farcting } \\
(\mathrm{n}=64)\end{array}$ \\
\hline $\begin{array}{l}\text { Mean age (years) } \\
\text { No with transmural infarct }\end{array}$ & $55 \cdot 9$ & $55 \cdot 9$ & $56 \cdot 8$ & $53 \cdot 8$ & $57 \cdot 5$ \\
No with non-transmural infarct & 23 & 60 & 58 & 13 & 45 \\
Previous myocardial infarction & 23 & 21 & 21 & 2 & 19 \\
No with diabetes & 8 & & 16 & 3 & 13 \\
No still smoking & 48 & & 11 & 4 & 7 \\
No taking NSAID & & & 18 & 1 & 17 \\
No taking warfarin & & & 8 & & 8 \\
(1-18 months) & & & 8 & & \\
\hline
\end{tabular}

NSAID = Non-steroidal anti-inflammatory drugs.
The 15 patients who reinfarcted between one and 18 months after their index myocardial infarction had a lower mean absolute platelet frequency at $5 \mathrm{fl}$ than those patients who did not reinfarct, but this difference was not significant (fig 4).

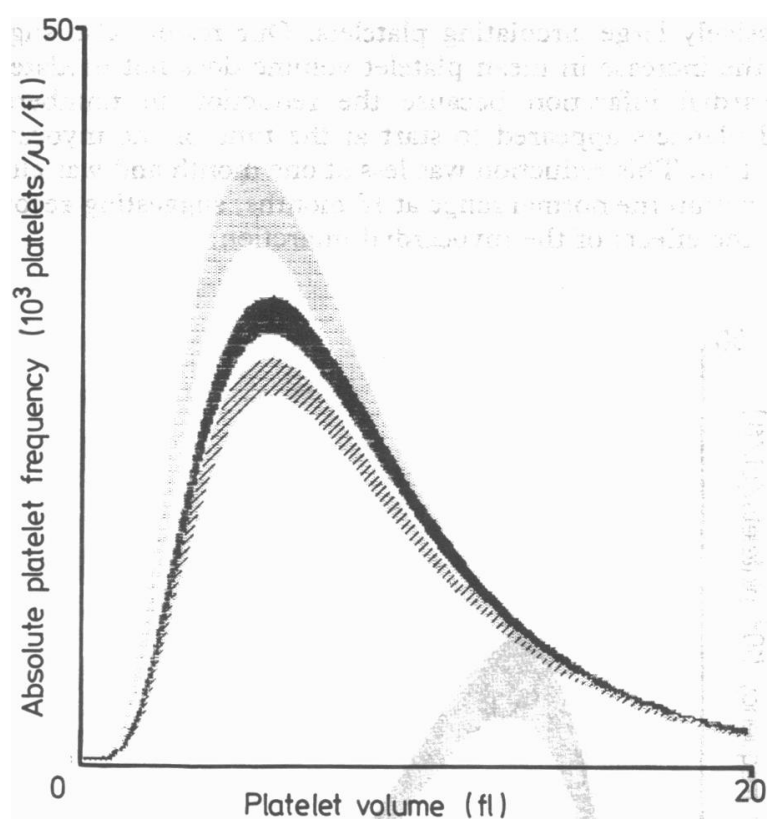

FIG 2-Distribution of mean platelet volume distributions in patients on day 1 ( ) and day 3 (एT⿰亻) after myocardial infarction and in controls (

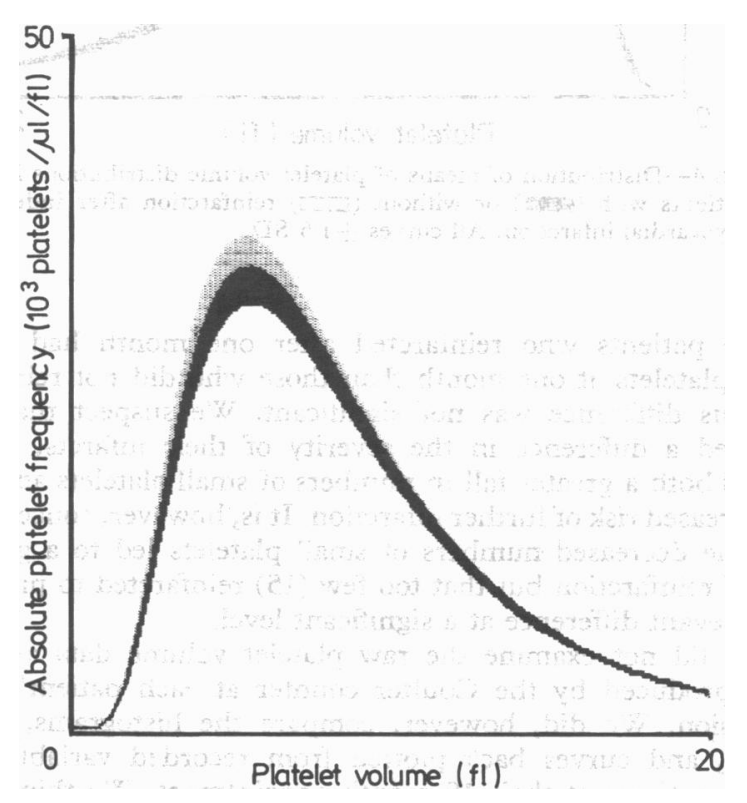

FIG 3-Distribution of means of platelet volume distributions in patients 18 months after myocardial infarction ( ) and in controls $(\square)$. All curves $\pm 1 \cdot 4 \mathrm{SD}$.

At no stage was there any significant difference in the absolute platelet frequencies for platelet volumes above $12 \mathrm{fl}$ for any of the patient groups studied compared with controls. The differences observed at $5 \mathrm{fl}$ were therefore not just due to the previously described reduction in total platelet count. ${ }^{1}$

Within each group there was the expected significant negative regression of mean platelet volume on platelet count $(p<0.05),{ }^{5}$ and there was also a significant positive regression of mean platelet volume on platelet distribution width $(p<0.05)$. The increased mean platelet volume in patients at their original admission was, however, greater than could be accounted for by these regressions together. 


\section{Discussion}

Our results show that the increase in mean platelet volume after acute infarction is due not to an excess of large platelets but to a deficit of small ones, which is evidence against the hypothesis that myocardial infarctions are precipitated by excessively large circulating platelets. Our results also suggest that the increase in mean platelet volume does not predate the myocardial infarction because the reduction in numbers of small platelets appeared to start at the time of the myocardial infarction. This reduction was less at one month and was almost back within the normal range at 18 months, suggesting recovery from the effects of the myocardial infarction.

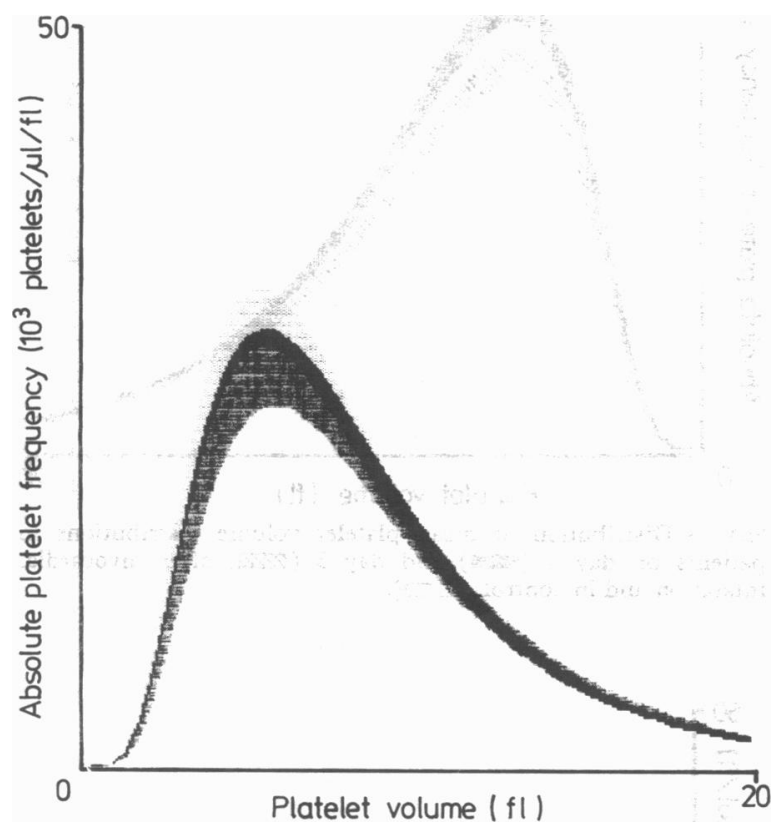

FIG 4-Distribution of means of platelet volume distributions in patients with ( $\square$ ) or without ( $\square$ ) reinfarction after index myocardial infarction. All curves $\pm 1.5 \mathrm{SD}$.

The patients who reinfarcted after one month had fewer small platelets at one month than those who did not reinfarct, but this difference was not significant. We suspect that this reflected a difference in the severity of their infarcts, which caused both a greater fall in numbers of small platelets and also an increased risk of further infarction. It is, however, conceivable that the decreased numbers of small platelets led to a greater risk of reinfarction but that too few (15) reinfarcted to produce the relevant difference at a significant level.

We did not examine the raw platelet volume data as they were produced by the Coulter counter at each patient's first admission. We did, however, compare the histograms, fitted curves, and curves back plotted from recorded variables for all the patients at their 18 month appointment. We think that the differences were not important, particularly as mean platelet volume itself was calculated from the fitted curve rather than from the raw histogram data. This is, of course, open to the criticism that any differences between histogram and fitted curve would be much more likely to show up at the first measurement after infarction than 18 months later (increase in mean platelet volume being greatest then) and that we failed to notice a deviation of the raw histograms from the fitted curve. (The Coulter counter is supposed to warn the operator if the histogram deviates appreciably from the best log normal curve it can fit. It did not do so for any of our patients at any stage, but it has been reported that it gives this warning very much less often than it should do. ${ }^{6}$ )

Possible explanations for the reduced numbers of small platelets without reduction in the larger ones include the following: (1) All platelets may be generally consumed but larger ones replaced more rapidly. Although larger platelets were once considered to be younger ones, this is now questioned. ${ }^{4}$ When the marrow is stressed, however, the average size of rapidly produced platelets is larger, ${ }^{7}$ and we may therefore have observed the result of a partially compensated thrombocytolytic state. (2) Only small platelets may be consumed. As platelets are activated small ones may possibly become exhausted and be removed from the circulation before larger ones. (3) There may be an unrecognised control system for platelet count that takes more account of circulating large volume platelets than of small. If so, a pre-existing reduction in numbers of small platelets might be accentuated by lack of feedback control for these platelets. This theory is partially supported by some evidence in our study that numbers of large platelets appear to be more tightly controlled than numbers of small ones: within all our patient groups the standard deviation of the absolute platelet frequencies at $20 \mathrm{fl}$ was a smaller fraction of their mean (roughly $6 \%$ ) than at $5 \mathrm{fl}$ (roughly 10\%). (4) Bone marrow production of small platelets may be reduced.

If any of the first three explanations were correct it would be in agreement with the finding that the duration of platelet survival is shortened in patients with ischaemic heart disease. ${ }^{8}{ }^{9}$ Determining the relative survival times of small and large platelets in normal patients and in those with acute myocardial infarction would be of interest as this would help to decide between the various explanations.

In conclusion, the reported rise in mean platelet volume after myocardial infarction appears to be due to a deficit of small platelets rather than an increase in large ones. These changes are probably the result rather than the cause of myocardial infarction.

We thank Mr A Lawton for statistical advice; Dr M Clarke and Dr J A S Davis for permission to include their patients in the study; and the staff of the medical illustration department.

\section{References}

1 Cameron HA, Phillips R, Ibbotson RM, Carson PHM. Platelet size in myocardial infarction. $B r$ Med $\mathcal{F} 1983 ; 287: 449-51$.

infarction. Br Med 7 1983;287:449-51. platelets in myocardial infarction. Br Med $\dot{\mathscr{f}} 1983 ; 287: 456-8$.

3 Eldor A, Avitzour M, Or R, Hanna R, Penchas S. Prediction of haemorrhagic diathesis in thrombocytopenia by mean platelet volume. Br Med $\mathcal{f} 1982 ; 285$ 397-400.

4 Trowbridge EA, Martin JF, Slater DN. Evidence for a theory of physical ragmentation of megakaryocytes implying that all platelets are produced in the pulmonary circulation. Thromb Res $1982 ; 28: 461-75$.

5 Giles C. The platelet count and mean platelet volume. Br f Haematol $1981 ; 48: 31-7$. Guthrie DL, Campbell SR, Maidment NJM. Platelet counting errors with the Coulter counter model S Plus. Chinical and Laboraty arpatkin S, Garg SK. The mato

Brf Haematol 1974;26:307. 2 . Platelet survival and development of coronary artery disease in the young adult: effects of cigarette smoking, strong family history, and medical therapy. Circulation 1981;63:546-51.

9 Mehta J, Mehta P, Pepine CJ. Platelet aggregation in aortic and coronary venous blood in patients with and without coronary artery disease. Circulation 1978;58 881.

(Accepted 24 September 1984)

\section{Shredding of manuscripts}

From 1 January 1985 articles submitted for publication will not be returned. Authors whose papers are rejected will be advised of the decision, and the manuscripts will be kept under security for three months, to deal with any inquiries, and then destroyed by shredding. Hence we would prefer to receive for consideration photostats or copies produced by word processor (see $B M F 13$ October, $\mathrm{p} 942$ ), though we do, of course, still need three copies. 